\title{
El tratamiento documental a fin de siglo
}

\author{
ANTULIO SÁNCHEZ \\ Universidad Autónoma de México, Iztapalapa \\ E-mail: antulio@ mailcity.com
}

\begin{abstract}
RESUMEN
Se cuestionan las posibles consecuencias culturales que puedan acarrear las tecnologías 'emergentes', sobre todo para las actividades bibliotecarias y bibliotecológicas. Y se reflexiona sobre las ideas de cultura y conocimiento con base en lo social y lo cognitivo intentando dar cuenta de la relación entre pensamiento y cultura. Pero las tecnologías actuales alteran todos los ámbitos del ejercicio intelectual a partir del uso de su piedra angular: la simulación, recurso que invade todas las esferas del quehacer humano y que mucho tiene que ver con la ruptura epistemológica que se presenta en nuestro campo. Tales nuevos tratamientos de la información demandan una constante actualización porque la materia de trabajo ha desbordado su geografía y trascendido nuestras cuatro paredes. El mejor tratamiento que se exige de los datos y la información, redefinirá a las mismas universidades y las bibliotecas como interfases entre el sabery su función social.
\end{abstract}

\section{THE DOCUMENT AND ITSTREATMENT AT THE END OF THE CENTURY ANTULIO SÁNCHEZ}

\begin{abstract}
Questions are raised regarding the effects of emerging technology on libraries and Library Science, and a reflection on the relationship between thought and culture- based upon the social and cognitive spheres of the ideas of culture and knowledge- is offered. The keystone of theses emerging technologies, simulation, alters every aspect of intellectual activity, invading a wide range of human endeavor and, furthermore, is in many ways responsible for the epistemological rupture in our field. Such new treatment of information demands constant updating because, through these technologies, documents are taken outside of their geographic context, transcending our four walls. The treatment required by data and information will redefine the universities and libraries themselves and their role as intermediaries between knowledge and their social function.
\end{abstract}

\section{CULT URA Y SABER}

To cabe dudaque en los tiempos que corren el tratamiento delainformación no es 1 imaginable sin los medios de comunicación denominados emergentes. Las interacciones humanas, lo financiero, la educación, la política, el tratamiento documental

Trabajo recibido el 21 de abril de 1999

Trabajo aceptado

el 25 de mayo de 1999 
son sometidos a una profunda alteración por estas tecnologías. Con las redes de computación y los procesos de digitalización, de forma más general, estamos ante una continuación radical de lo que habían puesto en funcionamiento las tecnologías precedentes o convencionales en cuanto a tratamiento de la información. Este acelerado proceso que viven las sociedades hoy cuestiona las consecuencias culturales de tales tecnologías y sus efectos en actividades como las bibliotecarias y bibliotecológicas. Pero antes de hablar específicamente de esto, quisiera hacer algunas reflexiones sobre las ideas de cultura y conocimiento.

Ampliay sin resultado final ha sido la discusión en el campo de las ciencias sociales acerca de si los seres humanos son afectados culturalmente por los aportes intelectuales y técnicos o si bien es la cultura la que produce los cambios en el terreno de las ideas. Son éstas las dos perspectivas que existen (social y cognitiva) para dar cuenta de la relación entre pensamiento y cultura. Para D urkheim constituía un hecho que las estructuras de pensamiento eran producto de la naturaleza social: la denominada representación colectiva no sólo es el conjunto de imágenes que se comparten a nivel grupal sobre lo que se es como comunidad y mundo, sino también el factor que hace posible la mismavida colectiva o social. ${ }^{1}$ En el mismo sentido Marx ${ }^{2}$ sostenía que el entorno cultural y la dinámica del pensamiento siempre han estado subordinados a los modos de producción: según Marx uno piensa de acuerdo a lo que hace. Weber, por el contrario, opinaba que los factores que conforman la ética protestante, su auge, son los que a la larga llevaron al desarrollo del capitalismo; de esta manera, el sistema capitalista sería consecuencia de un proceso racional: una forma de racionalidad entre medios y fines favorecería su despliegue. ${ }^{3} \mathrm{Así}$, para Weber, la cultura es el resultado o el producto de actividades cognitivas.

La idea de que las cuestiones sociales derivan de nuevas formas de organización de la estructura cognitiva, o de que proceden del desenvolvimiento cultural, constituyen pues las dos posturas que existen sobre el movimiento cultural. ${ }^{4}$ Sin embargo por sí mismas las cuestiones cognitivas no afectan la vida cultural, ya que para que eso se dées necesaria una nueva forma de relacionarse con ella, una dinámica que fa vorezca distintas formas de leer el entorno: cuando se presenta una interpretación nueva sobre la sociedad, por ejemplo, se genera una forma diferente de concebir el mundo y de ubicar al hombre en él. Las nuevas tecnologías, sobre todo las relacionadas con la cuestión cognitiva, contribuyen a darle paso a formas diferentes de gestar el saber que se reflejan en otros ámbitos: planes de estudio, el tratamiento documental, el imaginario colectivo, y se alteran las pautas culturales y se da pie a la creación de disciplinas intelectuales. ${ }^{5}$ Pero esta contribución se da también gracias a un ambiente que proporciona la base para que tenga eco laforma de operar propiadela tecnología.

1 Emile D urkheim. Las fomas dementales dela vida rdigiosa, Alianza, Madrid, 1993.

2 Carlos Marx. El capital, FCE, México, 1985.

3 Max Weber. La ática protetanteyd esṕnitu de capitalismo Artes gráficas, Buenos Aires, 1974.

4 D avid R. Olson. El mundosdbred papd, Gedisa, Barcelona, 1998.

5 J. G oody. Lalớġa dela escriturayla arganizacióndela sociedad Alianza, Madrid, 1990. 


\section{InvestigadónBiblictedógica V. 13 No. 26 enero/ junio de 1999}

No hay, pues, una sociedad natural construida por seres humanos naturales, ausentes o sin "determinación" social alguna. Toda sociedad o comunidad es un producto cultural: el hombre al construir tecnologías y significar su entorno, no se disocia de los objetos que construye, los cuales modifican su imaginario colectivo e individual. Más aún cuando trabajamos con nuevas herramientas tecnológicas, resignificamos esas actividades; es decir, las marcamos o las identificamos dentro de un campo simbólico que nos ha conformado previamente. Es la interrelación entre tecnología y cultura lo que genera nuevos campos simbólicos y favorece un imaginario distinto.

Hablar de la cultura oral o escrita como categorías culturales es referirse a técnicas de comunicación, de interpretación, y a prácticas culturales que son históricas y cuya validez y significado se respaldan en criterios de uso que cambian conformelas sociedades se modifican. Sin embargo, a pesar de que las mismas tendencias de comunicación en la red caminan velozmente hacia la alta interacción (como la misma realidad virtual) la realidad es que toda forma de escritura favorece una interpretación, ya que la transparencia absoluta nunca podrá ser lograda en la comunicación. Siempre estaremos ante un lenguaje que para desplegarse acudirá a signos, aformas recientes que representan el entorno y favorecen las interacciones humanas. ${ }^{6}$

\section{SIMULACIÓN Y LENGUAJE}

La cultura escrita tiene sus peculiaridades en lo referente a sus efectosy distorsiones. Como genuino producto de la representación también ella genera abusos, mitos y atropellos. Como toda tecnología, no está a salvo de usos erróneos. A tal grado es esto así, que Levi Straus ha dicho: "La escritura [produce] cambios profundos en las condiciones de vida de nuestra raza, y todas esas transformaciones deben haber sido de índole intelectual [...] sin embargo, nada de lo que sabemos sobre la escritura, sobre su papel en la evolución, puede justificar esta concepción. Si queremos correlacionar la aparición de la escritura con otras características de la civilización, debemos buscar en otra parte. [...] Si mi hipótesis es correcta, la función primaria dela escritura, como medio de comunicación, es facilitar la esclavitud de otros seres humanos. El uso de la escritura con fines desinteresados, y con vistas a satisfacer el espíritu en el campo de las ciencias y las artes, es un resultado secundario de su invención (y tal vez no sea sino una manera de reforzar, justificar o disimular su función primaria)". Claude Levi-Strauss. Tristestrópices, Paidós, Barcelona, 1997. A esto no ha escapado la misma cibernética, incluso lo ha potenciado; de su largay estrecha relación con lo militar es de donde proceden sus aportes. ${ }^{7}$

No obstante hoy es un hecho que las tecnologías emergentes de comunicación alteran todos los ámbitos del ejercicio intelectual, sobre todo por su piedra angular: la simulación o digitalización. El diccionario indica que simular es representar alguna

6 Antulio Sánchez. "Virtualidad y comunicación”, Topodilo UAM-I, núm 44, enero-febrero de 1997.

7 Katie Hafnery Matthew Lyon. Wherevizardsstayuplate Thearignsoftheinteme, Simon and schuster, Nueva York, 1996. 
cosa, fingir lo que no es, ${ }^{8}$ pero lo cierto es que simular en las diversas plataformas computacionales es un proceso real y medible, una cuestión que toca los aspectos relacionados con los electrones. Más allá de esto, simular es emplear un nuevo lenguaje en la medida en que su uso se extiende a los diversos campos de la cultura, y en que la misma tendencia cultural se apoya en modelizaciones icónicas. La simulación se ha convertido en una poderosa herramienta que alcanza los terrenos más increíbles, en una cuestión fundamental para el conocimiento e incluso para la manera de reflexionar. La simulación es así un aspecto que invade diversos sectores culturales. Al ser una experiencia multisensorial se transforma en un dispositivo amigable, pero en la misma medida se vuelve una vía enajenante y aplastante. Su base operativa está en los modelos, con ellos lo representado se convierte en una cuestión plástica, ágil, que da oportunidad para que lo simulado sea rectificado en tiempo real, pero al mismo tiempo le da vida perentoria.

Este es un cambio surgido tanto por las continuas y aceleradas transformaciones que se presentan en el campo de las nuevas tecnologías, como por una dinámica tecnológica imparable; un despliegue cultural que se remonta a la modernidad y que exige un proceso de aceleración y tratamiento de las informaciones con el fin de actuar de mejor manera sobre el entorno. Es la conjunción de ambos factores lo que hace en buena medida que la simulación sea en el presente un instrumento que hainvadido las distintas esferas del quehacer humano.

\section{EL TERRENO DOCUMENTAL}

La simulación está transformando ampliamente el tratamiento documental de lo que es dicho campo. Con la simulación, con la combinación de lo digital y lo predigital, se ofrece la posibilidad de que aparezcan nuevos objetos de pensamiento, de reflexión, al menos para todos los interesados en los sistemas de inscripción, de escritura, de almacenamiento, de obtención de información, de difusión, etcétera. Las tecnologías de la simulación o digitalización (escudriñamiento o escaneo, reconocimiento óptico de caracteres, lingǘstica computacional, bases de datos...) continúan desarrollándose al lado de las cuestiones gráficas en la investigación en los terrenos civil y militar o en el corazón mismo del sistema empresarial.

D esde la perspectiva de la documentación, las prácticas documentales exceden cada vez de forma más evidentelas instituciones públicas abocadas a lo documental. La ambición de P. 0 tlet $^{9}$ de sostener que los documentos están más allá del texto escrito, de las gráficas, adquiere mayor solidez en la medida en que el común denominador se vuelve un compilador de información y para el que la simulación juega un papel decisivo. Hoy el campo bibliográfico se ha desterritorializado de tal forma que la labor del bibliotecario se ha extendido, se ha hecho indispensable, pero al mismo tiempo su trabajo se ha vuelto más titánico: más que seguir inmersos en un universo

8 Dicionanioilustradbdelalengra españda, Barcelona, 1980.

9 Otlet. TraitédeDœumtatation: LeLivesurleLive, Mundaneum, Bruselas, 1989. 
enciclopédico se trata ahora de idearregistros eficaces de carácter cosmopédico, de pensar en términos locales sobre un registro global de aportes bibliográficos, sobre las fuentes digitales diseminadas en distintas partes del mundo. Pero más que de acumular las obras se trata de tener una clara idea de cómo acceder al conocimiento frontera 0 a los estados del arte en los diversos campos del saber, ya que esto se hará sólo a través de la red, de forma virtual. Tales tratamientos de la información demandan una constante actualización, un sistema de clasificación ágil y al alcance de la mayoría de los usuarios. Por tanto el especialista en el tratamiento documental tiene que incorporar estos criterios en sus actividades, incluso debe dominar cada vez más el lenguaje computacional y estar al tanto de una variedad de bases de datos relativos a las cuestiones documentales y a los programas computacionales que le faciliten su tarea.

Los progresos de lo digital en relación con lo documental tienen que ver con el almacenamiento, la comprensión de datos, el acceso a los documentos, la transmisión, la circulación, la manipulación, laimpresión, su accesibilidad. A unque es pertinente hacer notar que la mayor parte de las bases de datos actuales que se refieren a cuestiones bibliográficas son inadecuadas en cuanto el mismo acopio, la falta de imágenes (en la mayoría de los casos), la interpretación y la semántica de acceso alos contenidos dejan mucho que desear.

Podemos decir que en todos los campos se presenta una ruptura espistemológica, y que por tanto las cuestiones relativas a la documental no tienen por qué permanecer sin alteración. A unque tal vez podemos decir que el cine y el video ya habían afectado el ejercicio documental y la recopilación de materiales. D e esta forma, la ruptura fundamental que se ve en algunos niveles, pero sobre todo en el contexto de cómo integrar los materiales tratados ya de forma digital en el ámbito bibliotecario, conduce ala conformación de nuevas memorias, a distintas cuestiones relacionadas con el tratamiento de los datos y con el servicio que las bibliotecas les ofrecen a los usuarios.

El perfeccionamiento intenso quelas salas y las bibliotecas han sufrido en las últimas décadas, lleva a pensar que dentro de poco estaremos ante el advenimiento de digitecas que se agregarán a las bibliotecas, videotecas y filmotecas. Esto nos llevará a readecuar las funciones y los espacios, a pensar en nuevas zonas de consulta y a poner en marchaun tratamiento de las informaciones y las fuentes de una forma distinta, para lo cual también se necesitarán normas para descripción bibliográfica, la indexación, la constitución de catálogos, etcétera; que se pueden considerar como los indicadores de los documentos tradicionales.

En esto, por supuesto, habrá que tomar en cuenta ciertas consideraciones. Por ejemplo, se piensa que muchas de las nuevas clasificaciones que se hacen de la información en Internet, son asunto exclusivo del personal técnico, cuando lo cierto es que atañe a todos los interesados en el desarrollo educativo, cultural y en las cuestiones informativas tomadas en un sentido amplio. Si bien es cierto que por laforma en que se ha desarrollado la red muchas cuestiones sobre su operación o funcionamiento han recaído en personal técnico, también es un hecho que eso se debe en gran medida a que los demás usuarios de estos medios, quienes no tenemos que ver con las 
cuestiones técnicas en específico, lo hemos aceptado con nuestras actitudes: pensamos que eso es una cosa tan complicada que no podemos intervenir, que es un asunto de especialistas.

Una de las tareas por efectuar y que requiere de convenios y acuerdos al nivel global, y que por eso mismo no es asunto nada fácil, es pasar a formato digital las obras que se tienen en las bibliotecas. Es cierto que esto también habla de readecuar una obsoleta estructura de derechos de autor, de convenios y de acuerdos con las editoriales. Por el momento ya se ponen obras que son de uso público en la red, tales son los casos de proyectos como "G utenberg" o "Memoria del mundo" de la Unesco, en donde el objetivo es pasar a formato digital todas las obras que de acuerdo con las actuales leyes de derechos de autor ya son de uso público. Sin embargo en español no contamos con un sólido proyecto que contemple esta posibilidad de tener a la mano una amplia base de datos que contenga toda una bibliografía sobre diversas disciplinas y regiones de habla hispana.

La digitecas o bibliotecas multimedia deben tomar en consideración el grueso de sus futuros usuarios, que en su mayoría estarán más acostumbrados a las cuestiones digitales, pero también deben poner atención en el aspecto social de esto. D igitalizar las obras es algo que debe hacerse bajo la perspectiva de que la función social de las bibliotecas se incremente, y me parece que ésa puede ser una de las grandes perspectivas de las nuevas tecnologías si se sabe encauzar. Se debe facilitar el libre acceso a las informaciones, y hacer una compilación de una memoria extendida y del saber que se reúna o compile en diversas lenguas. Esta conservación de las obras deberá, de preferencia, pensarse como la posibilidad de tener distintas formas de fuentes: impresas, imagen y sonido; fuentes que permitan llegar a la concreción de auténticos espacios documentales multimedia. Esta es la biblioteca por venir, una digiteca capaz de contener las fuentes y documentos más diversos de consulta, que esté unidaa Internet y cuente con salas amplias que le ofrezcan la conexión a todos los interesados en hacerla.

En fin la biblioteca o digiteca que se requiere y se ve aproximar deberá permitirle a sus usuarios optar por distintos caminos (ver, simular o representar de otra manera), y les allegará diversos dispositivos para hacer una mejor consulta sobre cualquier tema 0 fenómeno. El bibliotecólogo es un pilar básico y necesario de esta época en donde la actualización y la generación de conocimiento a través de las fuentes informativas es tan importante. Los bibliotecólogosy su espacio inmediato de trabajo se desterritorializan, ya no sólo están adscritos a una zona de cuatro paredes, sus fuentes y materia de trabajo han desbordado su geografía. Se volverán nómadas inmersos en la búsqueda de las fuentes. Hoy más que nunca tienen una labor fundamental, pues en ellos recae también la función esencial de ofrecer un mejor tratamiento de los datos y la información, una labor básica que redefinirá a las mismas universidades y bibliotecas como interfases entre el saber y su función social a fin de siglo y milenio. 